\title{
EFFECT OF AMPLITUDE AND INSPIRATORY TIME IN A BENCH MODEL OF NON- INVASIVE HIGH FREQUENCY OSCILLATORY VENTILATION THROUGH NASAL PRONGS
}

D. De Luca, M. Piastra, G. Conti

PICU, University Hospital 'A.Gemelli', Catholic University of the Sacred Heart, Roma, Italy

Background and aims: Nasal high frequency oscillatory ventilation (nHFOV) has been proposed to combine the advantages of oscillatory pressure waveform and of non-invasive interface. We studied the effect of oscillation amplitude and inspiratory time on the pressure transmission and stroke volume delivered through different nasal prongs.

Methods: A bench model of nHFOV was built connecting SM3100A oscillator tubings via two differently sized nasal prongs, to a neonatal lung model carrying mechanical properties of recovering RDS. A standard circuit with no nasal prongs was used as control. Tidal volume $\left(\mathrm{T}_{\mathrm{v}}\right)$, oscillatory pressure ratio $\left(\Delta \mathrm{P}_{\text {dist }} \Delta \mathrm{P}_{\text {prox }}\right)$ and ventilation $\left(\mathrm{DCO}_{2}\right)$ were measured across a range of amplitudes and with inspiratory time (IT) set at $33 \%$ and $50 \%$. Measurements were performed with a low-dead space hot wire anemometer coupled with a pressure transducer, specifically validated for neonatal ventilation.

Results: $\mathrm{T}_{\mathrm{v}}, \Delta \mathrm{P}_{\text {dist }} \Delta \mathrm{P}_{\text {prox }}$ and $\mathrm{DCO}_{2}$ were $83 \%, 40 \%$ and $71 \%$, respectively, of those provided with the control circuit. No differences were noticed between small and large prongs. $\mathrm{T}_{\mathrm{v}}$ and $\Delta \mathrm{P}_{\text {prox }}$ were linked by a quadratic relationship and $\mathrm{T}_{\mathrm{v}}$ plateaus for amplitude values $>65 \mathrm{cmH}_{2} \mathrm{O} . \Delta \mathrm{P}_{\text {dist }} \Delta \mathrm{P}_{\text {prox }}$ shows the same tendency. Same results were obtained with both types of prongs and with increasing IT. On the whole, mean $\mathrm{T}_{\mathrm{v}}$ was higher with IT at $50 \%$ than at $33 \%(2.4 \mathrm{~mL} v s 1.4 \mathrm{~mL} ; p<0.001)$.

Conclusions: Changing oscillation amplitude significantly affect ventilation during nHFOV and this effect seems greater than that obtained by varying the frequency. $50 \%$ IT always provides an higher $\mathrm{T}_{\mathrm{v}}$ delivery and ventilation. 